\title{
Effects of Electric Fields on Protein Unfolding and Aggregation: Influence on Edible Films Formation
}

\author{
Ricardo N. Pereira, ${ }^{\star}$ Bartolomeu W. S. Souza, Miguel A. Cerqueira, José A. Teixeira, and \\ António A. Vicente \\ IBB-Institute for Biotechnology and Bioengineering, Centre for Biological Engineering, Universidade do \\ Minho Campus de Gualtar, 4700-035 Braga, Portugal
}

Received June 17, 2010; Revised Manuscript Received September 8, 2010

\begin{abstract}
Electric fields application is receiving increased attention because of its uniform heating of liquids. The mechanisms of unfolding and aggregation of whey proteins during ohmic heating may influence properties of edible films made thereof. The aim of this work was to evaluate the effects of ohmic heating on physical and structural properties of whey protein edible films and compare them with those obtained by conventional heating. The results showed that ohmic heating determined less aggregation and lower concentration of free sulphydryls in film-forming solutions. Ohmic films were thinner, less permeable to water vapor and presented nearly the same mechanical properties of conventional films. Ohmic heating induced protein conformational changes by increasing the contents of $\beta$-sheet structures in the film network. This work emphasized the effects of ohmic heating in unfolding and aggregation mechanisms of whey proteins during heat denaturation, which determined the production of protein edible films with distinctive properties.
\end{abstract}

\section{Introduction}

Edible films are used in the food industry to extend shelf life of food products and prevent their quality changes by acting as barriers to the migration of flavours, aroma, oxygen, lipids, moisture, and mechanical damages. The ability of globular proteins to produce edible films has been intensively reviewed through the last two decades. ${ }^{1-6}$ Among other proteins, whey protein fractions such as $\beta$-Lg, $\alpha$-Lac, and whey protein isolate (WPI) present high nutritional value and unique functional properties. They offer a great potential for manufacture of transparent, bland, and flexible edible films, which act as moderate barriers to the transport of moisture, present superior aroma, lipid barrier properties, and low oxygen permeability at low relative humidity (RH) ${ }^{7-10}$ For instance, at RH below $50 \%$, the oxygen permeability remains quite constant; however, for RH above $50 \%$, oxygen permeability can increase exponentially. ${ }^{11}$ Moreover, the production of edible whey protein films may also represent a valuable means of utilization of excess whey, ${ }^{12}$ a dairy industry byproduct that needs to be valorized. Recently, studies on WPI films with several formulations and innovative functionalities have been carried out. ${ }^{1,4,13}$ WPI is mainly composed of $\beta$-lactoglobulin $(\beta$-Lg), $\alpha$-lactalbumin $(\alpha-$ Lac), bovine serum albumin (BSA), and immunoglobulins. ${ }^{14}$ The film-forming abilities of WPI are dominated by technofunctional properties of $\beta$ - $\mathrm{Lg}$, the most abundant protein in whey. ${ }^{15}$

Production of intact WPI-based films generally needs the following steps: (I) heat denaturation of globular whey proteins; (II) incorporation of a minimal content of plasticizer to promote disruption of intermolecular association and increase intermolecular spacing between the biopolymers, resulting in a reduction of films' brittleness and providing flexibility to the final film; ${ }^{16}$ and (III) dehydration, under a controlled RH atmosphere, of the film-forming solution. ${ }^{1,15,17}$

* To whom correspondence should be addressed. E-mail: rpereira@ deb.uminho.pt.
Heating of WPI is believed to induce disruption of the native conformation of globular whey proteins, resulting in the exposure to the solvent of free sulphydryl groups ( $\mathrm{SH}$ ), normally occluded within $\beta$ - Lg and BSA, and hydrophobic amino acid side chains. ${ }^{18} \mathrm{SH}$ may rapidly interchange with existing disulfide bonds to generate new inter- and intramolecular disulfide bonds. ${ }^{2}$ During heating, the role of sulphydryl/disulfide interchange may promote intermolecular disulfide bond formation, which together with intermolecular protein-protein interactions (such as entropic forces, dipolar, and electrostatic interactions) between unfolded "reactive" proteins determines protein aggregation. For the production of edible protein films, the formation of aggregates in the film-forming solutions (before drying) is required to form stiff and stretchable films. ${ }^{15}$

Ohmic heating $(\mathrm{OH})$ is receiving increased attention because of its uniform heating of liquids with faster heating rates, which enables us to obtain products of a superior quality to those processed by conventional heating technologies. ${ }^{19-21}$ This heating method involves the passage of an alternating electrical current through a food, which will heat because of internal energy dissipation according to Joule's law. During $\mathrm{OH}$ treatment, food behaves as a resistor in an electrical circuit. This technology offers great potential for use in a wide variety of food processing operations involving heat and mass transfer, such as blanching, evaporation, dehydration, fermentation, ${ }^{22}$ continuous cooking, and sterilization of viscous and liquid food. ${ }^{23}$ Very few works deal with the potential use of $\mathrm{OH}$ to produce edible films. For example, $\mathrm{OH}$ was used as a device for protein-lipid film formation, determining improvements on yield, rehydration capacity, and film formation rate and underlying the importance of avoiding partial overheating to ensure the good quality of soybean protein-lipid films. ${ }^{24}$ More recently, the effects of $\mathrm{OH}$ on the properties of chitosan coatings have been evaluated, ${ }^{25,26}$ and the authors concluded that the presence of moderate electric fields had also significant effects on the film's physical properties and structure, which were reflected on film transport properties. In particular, physical properties 
such as the solubility in water and the water vapor, oxygen, and carbon dioxide permeability coefficients showed a positive correlation with the application of an electric field. Moreover, the application of an electric field promoted changes in the crystallinity index and produced chitosan films with a more uniform surface, which may be related to a more uniform gel structure, leading to differences in terms of transport properties.

Given the biochemical structure of proteins, it is expectable that $\mathrm{OH}$ will influence their properties and hence their behavior. However, there is very little information available regarding the effects of $\mathrm{OH}$ on proteins and even less about edible films produced from ohmic heated WPI solutions. Because of rapid heat penetration rates and also because of the presence of moderate electric fields, $\mathrm{OH}$ possibly influences denaturation and aggregation mechanisms of whey proteins, affecting WPI film properties. In fact, it is possible that edible films manufactured from ohmic heated protein solutions would present particular physical, mechanical, and barrier properties, thus allowing the production of WPI films for particular applications. However no experimental work has been reported to confirm this until the present moment.

The objectives of this work were, on a comparative basis, to manufacture edible films produced from ohmic heated WPI solutions and characterize them in terms of their physical and structural properties and to compare such films with those obtained using conventional heating methods. The effects of heating (conventional and ohmic) on thermal aggregation of whey proteins, before drying and film formation, were also evaluated in an attempt to provide insight into the mechanisms that may be influencing the observed changes in films' properties.

\section{Material and Methods}

2.1. Preparation of Heated-Treated WPI. WPI powder (Lacprodan DI-9212) was kindly supplied by Arla Foods Ingredients (Viby, Denmark). WPI was essentially free of lactose (max $0.5 \%$ ) and fat (max $0.2 \%$ ) and had a protein content of $91 \%$ (of dry weight). We prepared aqueous solution of WPI ( $3 \% \mathrm{w} / \mathrm{w}$, protein) by dispersing WPI powder in a $0.05 \mathrm{M}$ phosphate buffer of disodium hydrogen phosphate and sodium dihydrogen phosphate (Riedel de Haën, Germany) buffered to $\mathrm{pH}$ 6.0. WPI solution was then stirred continuously overnight at refrigeration temperature $\left(5^{\circ} \mathrm{C}\right)$ to ensure full rehydration, and $\mathrm{pH}$ was adjusted to 6.8 with $1 \mathrm{M} \mathrm{NaOH}$ (Merck, Germany). To prepare heatdenatured films, $50 \mathrm{~mL}$ of the previously prepared WPI solution was heated at $85^{\circ} \mathrm{C}$ for $30 \mathrm{~min}$ by either ohmic or conventional heating and cooled to room temperature in an iced water bath. On the basis of preliminary experiments, the conditions for the preparation of WPI filmforming solutions referred to above, such as protein concentration (3\%), $\mathrm{pH}(6.8)$, buffer capacity $(0.05 \mathrm{M})$, and heating conditions $\left(85^{\circ} \mathrm{C}\right.$ up to $30 \mathrm{~min}$ ), were selected to avoid coagulation or gel formation during heating. Moreover, the conditions chosen, in terms of protein concentration and ionic strength, allowed an optimal starting electrical conductivity of the WPI solutions $\left(\sim 1400 \mu \mathrm{S} \cdot \mathrm{cm}^{-1}\right)$ for ohmic heating effect to take place.

2.1.1. Conventional Heating. Conventional heating experiments were performed in a double-walled water-jacketed reactor vessel $(3 \mathrm{~mm}$ of internal diameter and $100 \mathrm{~mm}$ height). During the heating, cycle temperature was controlled by circulating water from a temperaturecontrolled water bath. A magnetic stirrer was introduced inside the reactor vessel to homogenize the solution and improve heat transfer during the heating cycle. Temperature evolution, during conventional and ohmic heating experiments, was measured with a type-K thermocouple $\left( \pm 1^{\circ} \mathrm{C}\right.$, Omega, 709 , U.S.A.), placed at the geometric center of the sample volume and connected to a data logger (National Instruments, USB-9161, U.S.A.) working with Lab View 7 Express software (National Instruments, NI Data logger).

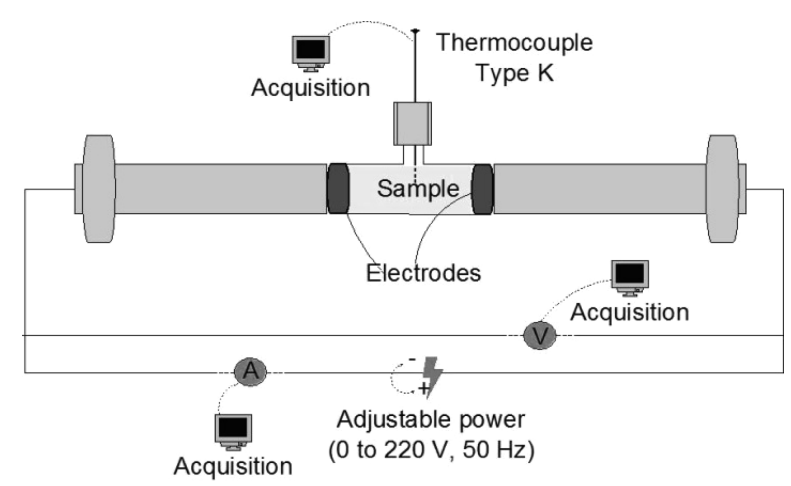

Figure 1. Bench-scale batch ohmic heater and data acquisition system used for ohmic heating treatments.

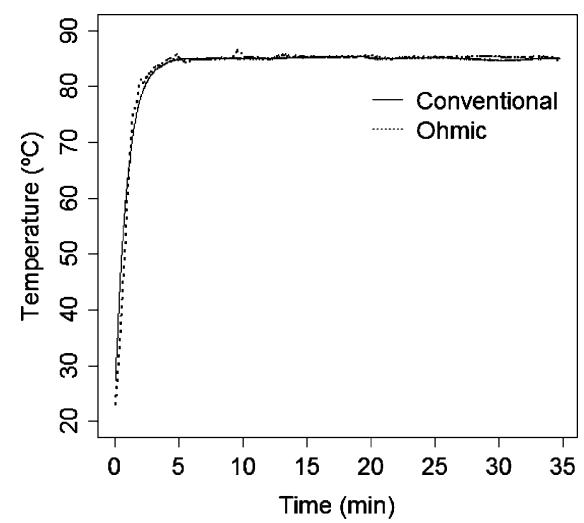

Figure 2. Example of similar thermal histories at $85^{\circ} \mathrm{C}$ (up to $30 \mathrm{~min}$ ) for conventional and ohmic heating treatments.

2.1.2. Ohmic Heating $(\mathrm{OH})$. $\mathrm{OH}$ treatments were performed in a concentrical cylindrical glass tube of $30 \mathrm{~cm}$ total length and an inner diameter of $2.3 \mathrm{~cm}$, with two inox electrodes isolated at each edge with Teflon caps (Figure 1). For the experiments, a gap between the electrodes of $10 \mathrm{~cm}$ (the treatment chamber) was used, and the supplied voltage ranged from 20 to $220 \mathrm{~V}$. For 30 min of holding at $85^{\circ} \mathrm{C}$, a nominal electrical field of $\sim 10 \mathrm{~V} \cdot \mathrm{cm}^{-1}$ was applied. The supplied voltage, and consequently temperature, was controlled through the use of a rheostat (Chuan Hsin, Taiwan) connected to the monophasic alternate current supply system $(231 \mathrm{~V}, 50 \mathrm{~Hz})$. During the experiments, the nominal electric field was varied through the rheostat to adjust the supplied voltage and simulate the thermal history of samples observed during conventional heating experiments (Figure 2). A close coincidence of the temperature profiles during the sample heating phase, in both conventional and ohmic treatments, is a necessary condition to evaluate the nonthermal effects of ohmic heating.

Temperature measurement was performed as previously described for conventional heating. A data logger was employed to record continuously and simultaneously voltage and current intensity across the samples during heating.

2.2. Characterization of WPI Heated Solutions. 2.2.1. Particle Size Analysis. The average size of WPI aggregates formed during heating treatments at $85{ }^{\circ} \mathrm{C}$ (conventional and ohmic) was measured by dynamic light scattering (DLS) using a Zetasizer Nano (ZEN 3600, Malvern Instruments, Malvern, U.K.) equipped with a $\mathrm{He}-\mathrm{Ne}$ laser of $632.8 \mathrm{~nm}$ and $4 \mathrm{~mW}$. We collected measurements of the dynamics of the scattered light by applying backscatter detection NIBS (noninvasive backscatter) at $173^{\circ}$, which reduces multiple scattering and allows higher concentrations to be measured. Average diffusion coefficients were determined by the method of cumulants fit and were translated into average particle diameters (Z-value) using the Stokes-Einstein relationship. The polydispersity (PDI) index, derived from cumulants analysis of the DLS measurements, which describes the width or the relative variance of the particle size distribution, was also evaluated. During heating experiments the total mass concentration is constant; 
therefore, scattering intensity is assumed to increase in proportion to an average molecular mass of the particles. ${ }^{27}$

Samples of $1 \mathrm{~mL}$ of unheated (control) and heated (conventionally and ohmically) WPI solutions were poured in disposable sizing cuvettes, and measurements were carried out, at least, in triplicate. The measurement cell was maintained at $25 \pm 0.5{ }^{\circ} \mathrm{C}$.

2.2.2. Determination of Free Sulphydryls $(\mathrm{SH})$. Free sulphydryl groups were determined in unheated (control) and heated WPI solutions immediately after processing. Ellman's 5,5'-dithiobis-(2-nitrobenzoic acid) or DTNB method, ${ }^{28}$ modified to react specifically with free sulphydryl groups in milk proteins, ${ }^{29}$ was adapted for determination of sulphydryl groups on WPI solutions. A $100 \mu \mathrm{L}$ sample of WPI solutions (unheated and heated) was diluted to $1 \mathrm{~mL}$ with phosphate buffer ( $5 \mathrm{mM}, \mathrm{pH} 8.0$,) and adjusted to $\mathrm{pH} 8.0$ with $1 \mathrm{M} \mathrm{NaOH}$. To this solution, $12 \mu \mathrm{L}$ of $5 \mathrm{mM}$ DTNB (Sigma-Aldrich, Spain), prepared in $\mathrm{pH} 8.0$ phosphate buffer, was added, and color development was allowed to proceed for $40 \mathrm{~min}$. Micellar protein was removed by centrifuging (Mikro 120 Microfuge, Hettinch, Germany) at $15558 \mathrm{~g}$ for $30 \mathrm{~min}$ at room temperature. The clear solution at the center of the centrifuge tube was removed with a syringe, and absorbance was read on a microplate reader (Biotech Synergy HT) at $412 \mathrm{~nm}$.

2.3. Conventional and Ohmic Film Formation. Glycerol (Gly) (Panreac, Barcelona, Spain) was added (as a plasticizer) to WPI solutions subjected to conventional and ohmic heating (as previously described) in a 1:3 ratio of Gly/WPI. After homogenizing, aliquots of $30 \mathrm{~mL}$ of conventional and ohmic WPI film-forming solutions were cast onto $8 \mathrm{~cm}$ diameter glass plates to maintain film thickness. Films were then dried in a convection oven at $35{ }^{\circ} \mathrm{C}$ for $12 \mathrm{~h}$. After this dehydration step, films were peeled from the plate and conditioned, at $20{ }^{\circ} \mathrm{C}$ during $48 \mathrm{~h}$, in desiccators at a controlled $\mathrm{RH}$ atmosphere of $50 \%$, for further property testing. For each property, a minimum of three replicates for each heating treatment were prepared.

2.4. Characterization of WPI Films. 2.4.1. Thickness. Film thickness was measured with a hand-held digital micrometer (Mitutoyo, Japan) having a sensitivity of $0.001 \mathrm{~mm}$. At least, 10 thickness measurements were taken on each testing sample in different randomly chosen points following WVP and preceding tensile tests. WVP and mechanical properties were calculated on the basis of average thickness values.

2.4.2. Permeance and Water Vapor Permeability (WVP) Measurement. The measurement of WVP was performed gravimetrically based on ASTM E96-92 method. ${ }^{25,30-32}$ The film was sealed on the top of a permeation cell containing distilled water (100\% RH; $2337 \mathrm{~Pa}$ vapor pressure at $\left.20{ }^{\circ} \mathrm{C}\right)$ and placed in a desiccator at $20^{\circ} \mathrm{C}$ and $0 \% \mathrm{RH}(0$ $\mathrm{Pa}$ water vapor pressure) containing silica. The cells were weighted at $2 \mathrm{~h}$ intervals during $10 \mathrm{~h}$. Steady-state and uniform water pressure conditions were assumed by keeping the air circulation constant outside the test cell by using a miniature fan inside the desiccator. ${ }^{32}$ Water vapor transmission rate (WVTR) was calculated using eq 1 of the Supporting Information, and WVP values were calculated through eqs $2-4$ of the Supporting Information using the WVP correction method. ${ }^{32,33}$

2.4.3. Film Moisture Content. To determine the moisture content (MC) of films, $\sim 50 \mathrm{mg}$ of film were dried in an oven at $105{ }^{\circ} \mathrm{C}$ $\left(\mathrm{MC}_{105^{\circ} \mathrm{C}}\right)$ during $24 \mathrm{~h}$ (until the equilibrium weight was attained). The weight loss of the sample was determined, from which the MC was calculated using eq 5 in the Supporting Information

2.4.4. Film Solubility. Film solubility in water was determined according to the method reported by Gontard et al. and Cuq et al. ${ }^{34,35}$ It was defined by the content of dry matter solubilized after $24 \mathrm{~h}$ of immersion in water. The initial dry matter content of each film was determined by drying to constant weight in an oven at $105{ }^{\circ} \mathrm{C}$, as previously described in section 2.4.3. Then, two disks of each film ( $2 \mathrm{~cm}$ diameter) were cut, weighed $\left(M_{\mathrm{i}}\right)$, and immersed in $50 \mathrm{~mL}$ of water. After $24 \mathrm{~h}$ of immersion at $20{ }^{\circ} \mathrm{C}$ under agitation ( $\left.60 \mathrm{rpm}\right)$, the pieces of film were taken out and dried to constant weight $\left(M_{\mathrm{f}}\right)$ in an oven at $105{ }^{\circ} \mathrm{C}$ to determine the weight of dry matter that did not solubilize in water. Film solubility was determined using eq 6 in the Supporting Information.

2.4.5. Surface Hydrophobicity. The sessile drop method, based on optical contact angle method, was used to estimate the surface hydrophobicity of the test films. Contact angle $(\theta)$ was determined with a face contact angle meter (OCA 20, Dataphysics, Germany) by the sessile drop method, ${ }^{36}$ in which a droplet of ultrapure water was deposited on the film surface with a $500 \mu \mathrm{L}$ precision syringe (Hamilton, Switzerland). The drop image was recorded by a video camera, and the profile of the droplet was numerically solved and fitted to the Laplace-Young equation. Five measurements were independently replicated per film sample and tripled per film batch. All measurements were performed both on the "air-side" of the films (face in contact with air) and on the "support side" (face in contact with the support) at $20 \pm 1{ }^{\circ} \mathrm{C}$.

2.4.6. Tensile Strength and Elongation at Break. Tensile strength (TS) and elongation at break (EB) were measured with an Instron universal testing machine (model 4500, Instron Corporation) following the guidelines of ASTM standard method D 882-91. The initial grip separation was set at $30 \mathrm{~mm}$, and the crosshead speed was set at 5 $\mathrm{mm} \cdot \mathrm{min}^{-1}$. TS was expressed in pascals and calculated by dividing the maximum load $(N)$ by the initial cross-sectional area $\left(\mathrm{m}^{2}\right)$ of the specimen. EB was calculated as the ratio of the final length at the point of sample rupture to the initial length of a specimen $(30 \mathrm{~mm})$ and expressed as a percentage. According to the ASTM standard, film strips with a length of $45 \mathrm{~mm}$ and a width of $20 \mathrm{~mm}$ were used. TS and EB tests were replicated at least three times for each type of film.

2.4.7. Fourier Transform Infrared Spectra. Fourier transform infrared spectra (FTIR) spectra were acquired with a Perkin-Elmer 16 PC spectrometer (Perkin-Elmer, Boston) using attenuated total reflectance (ATR) mode between 650 and $3500 \mathrm{~cm}^{-1}$. Each spectrum is the result of the average of 16 scans at $1 \mathrm{~cm}^{-1}$ resolution. For the analysis of protein secondary structure contents, spectra were curve-fitted in the $1600-1700 \mathrm{~cm}^{-1}$ (Amide I) and $1200-1350 \mathrm{~cm}^{-1}$ regions (Amide III) using Gaussian and Lorentzian functions. For all regions analyzed, a linear baseline was subtracted, and the absorbance was normalized with respect to the peak maximum to avoid undesirable intensity variations. ${ }^{15}$ Then, initial values of the peak positions were determined by Fourier deconvolution. Parameters of Fourier deconvolution were chosen after several trials to give reasonable fits and to obtain enough band narrowing to see the major components of amide bands. ${ }^{37}$ Spectra of WPI films have been deconvoluted with a Gaussian response function deconvolution filter constant of $77 \%$ and smoothing filter of $88 \%$. All data treatments were performed with Peakfit software version 4.12 (SYSTAT Software, Richmond, CA).

2.5. Statistical Analysis. All statistical analyses involving experimental data were performed using $\mathrm{R}$ software version 2.10.1.38

\section{Results}

3.1. Characterization of WPI Film-Forming Solutions. 3.1.1. Aggregation of Proteins. When WPI solutions were heated $\left(85^{\circ} \mathrm{C}\right.$, up to $\left.30 \mathrm{~min}\right)$, the average hydrodynamic diameter $(Z)$ of the whey protein aggregates was found to increase considerably in both heating treatments. However, $\mathrm{OH}$ produced smaller changes $(p<0.05)$ in whey protein aggregates' size when compared with conventional heating. Table 1 of the Supporting Information shows that WPI solutions treated by conventional heating presented a $Z$ of $86.0 \pm 0.5 \mathrm{~nm}$, whereas ohmic heating determined $Z$ values of $76.6 \pm 0.5 \mathrm{~nm}$. Overall, the whey protein aggregates' diameter increased about 57 and $67 \mathrm{~nm}$ during ohmic and conventional heating, respectively. The PDI decreased rapidly in the early stages of heating (results not shown) and then slowly increased to an identical plateau $(p>0.05)$ of $\sim 0.270$ in both heating treatments. The levels of aggregation of whey proteins observed were comparable to those 
of other literature reports. ${ }^{39}$ Comparisons with other works are always rather difficult because of the use of different experimental conditions, such as changes in model solutions ( $\mathrm{pH}$, ionic strength, protein concentration, presence of caseins), method of heating (slow or rapid), and heating conditions (time and temperature), which may determine different levels of aggregation or association of whey proteins. ${ }^{39-42}$ Throughout the present work, the changes observed between levels of whey protein aggregation under ohmic and conventional heating were very comparable and reproducible once the properties of WPI solutions ( $\mathrm{pH}$, ionic strength, protein concentration) and heating conditions (time and temperature) were carefully controlled.

3.1.2. Free Sulphydryl Groups (SH). Residual quantities of SH were present in unheated WPI solutions $(0.6 \mu \mathrm{mol}$ of SH per gram of WPI). At the end of heating treatments, concentrations of SH in WPI solution were 10 times higher than those observed in unheated WPI solutions. Results in Table 1 of the Supporting Information show that samples treated by conventional heating exhibited 2.2 more micromoles of SH per gram of WPI than samples treated by ohmic heating $(p<0.05)$. The calculated SH levels were slightly higher than the published values ${ }^{43-45}$ probably because of the use of both different experimental conditions (e.g., use of WPI instead of skim milk fractions) and analytical methods. Despite this, the results obtained are still in good agreement with published data, indicating unmasking and activation of SH groups in whey proteins upon extended heat treatment at temperatures above $70{ }^{\circ} \mathrm{C} .{ }^{44,46,47}$

3.2. Characterization of WPI Films. Table 2 in the Supporting Information shows the results for physical and mechanical characterization of WPI intact films. Films prepared from WPI/Gly (ratio of 3:1) and solutions with WPI contents of 3\% were enough for the formation of intact WPI films after both heating treatments (conventional and ohmic). However, under the same conditions but without heat treatment, WPI films cracked into small pieces when dried. These results are in accordance with previous studies on WPI solutions, which show that prolonged heat treatments and protein contents $>2.3 \mathrm{~g} /$ $100 \mathrm{~g}$ are necessary conditions to produce WPI intact films that can be handled without breaking. ${ }^{17,48}$

3.2.1. Solubility and Moisture Content. Ohmic and conventional films presented almost $20 \%$ of MC and were partially soluble in water, both showing $>50 \%$ of soluble matter (Table 2 of the Supporting Information). The type of heating treatment had no significant effect $(p>0.05)$ on films solubility and MCs. The insolubility in water of whey protein films has been attributed to the presence of high concentrations of intermolecular disulfide bonds. ${ }^{49}$ In the present work, the higher values of solubility may be explained by the lower content of WPI in the film-forming solutions $(\sim 3 \%)$, which led to a lower occurrence of intermolecular disulfide bonds. In general, protein concentrations of $5-10 \%$ are used to produced whey protein edible films, ${ }^{2,8,15}$ increasing then protein interactions and the film's insolubility.

3.2.2. Thickness. The thickness of films prepared through conventional heating ranges from 0.197 to $0.207 \mathrm{~mm}$. These values were slightly higher than those reported by other authors for whey protein films, ${ }^{3,17}$ essentially because of differences in film-forming solutions formulations and in the procedures used. Previous studies have shown that film thickness may vary essentially with WPI concentration and protein-plasticizer ratio. ${ }^{1,48}$ Control over film thickness is required for film uniformity, reliability of measured properties, and validity of comparisons between thickness-dependent properties of different films. ${ }^{50}$ Interestingly, for the same experimental conditions and casting procedures, WPI films prepared from $\mathrm{OH}$ presented a mean thickness of $0.175 \mathrm{~mm}$, which was significantly lower $(p<0.05)$ than that of films produced by conventional heating $(0.202 \mathrm{~mm})$. OH seems to have affected the properties of WPI film-forming solutions, which determined thinner films after the drying step.

3.2.3. Permeability Properties. Concerning the permeability properties, despite the ohmic film being $10 \%$ thinner than the conventional one, the same amount of water vapor passed through both films. Because WVP is the product of film permeance and thickness, ohmic films presented lower permeability to water vapor than conventional films $(p<0.05)$ because of the lower thickness of the former (Table 2 of the Supporting Information). It is well recognized that hydrophilic films, such as WPI films, often exhibit positive slope relationships between thickness and WVP. ${ }^{1,32,35,48}$ This thickness effect may be explained by the exponential relationship between thickness and the RH at the inner surface of the film. This calls for a modification of the permeance calculation. However, even when the modified calculation is used, the resulting WVP values are still thickness-dependent. WVP values for conventional and ohmic films, 0.602 and $0.663 \mathrm{~g} \cdot \mathrm{mm} \cdot \mathrm{kPa}^{-1} \cdot \mathrm{h}^{-1} \cdot \mathrm{m}^{-2}$, respectively, are in agreement with published data for WPI films, which can range from 0.2 to $6.4 \mathrm{~g} \cdot \mathrm{m} \cdot \mathrm{kPa}^{-1} \cdot \mathrm{h}^{-1} \cdot \mathrm{m}^{-2}$. ${ }^{6}$ However, it is important to notice that different chemical, structura1, and geometric conditions may impose various effects on the magnitude of edible film WVP values, thus causing difficulties in the use and comparison of permeability data. ${ }^{51}$

3.2.4. Mechanical Properties. No significant difference $(p>0.05)$ was observed for TS values between ohmic and conventional films. This may be attributed to the inclusion of film thickness in the calculation. ${ }^{52}$ Using a puncture test normalized for film thickness, several authors found that the normalized force at break was unaffected by film thickness. ${ }^{48}$ Conventional films presented significantly $(p<0.05)$ higher percentage of EB than ohmic films. The fact of conventional films being thicker and consequently with a greater cross sectional area than ohmic films may have permitted a greater extension under stress. ${ }^{48}$ However, it is important to note that for higher ranges of thickness values, which was the case of the ones observed in this study, other authors did not find a correlation between EB and thickness values. ${ }^{35,53}$

3.2.5. Surface Hydrophobicity. Surface hydrophobicity of films was evaluated through the measurement of the contact angle of water $(\theta)$ upon film surface by the sessile drop method. Quantitative differentiation between "hydrophobic" and "hydrophilic" surfaces is based on whether the water contact angle is $\theta>65^{\circ}$ or $\theta<65^{\circ}$, respectively. ${ }^{54}$ Therefore, conventional and ohmic WPI films can be considered to have hydrophilic surfaces, both presenting values of $\theta$ below $65^{\circ}$. However, the results from contact angle measurements suggest that surface hydrophobicity of WPI films is dependent on the choice of tested surfaces (air or support sides). For both treatments, the upward surface (air side) of films presented higher hydrophobicity than the downward surface (support side). During drying, the thin liquid film layer adhering to the support (support side) probably retained more water than the free surface (air side), preserving to a greater extent the hydrophilic proprieties. The ohmic heating treatment resulted in significant $(p<0.05)$ differences of contact angle values for the "air side" surfaces of WPI films; when both treatments were compared, the "air side" surfaces of ohmic films were more hydrophilic, with $\theta=54.9^{\circ}$, whereas the "air side" surfaces of conventional films were nearly hydrophobic, with 


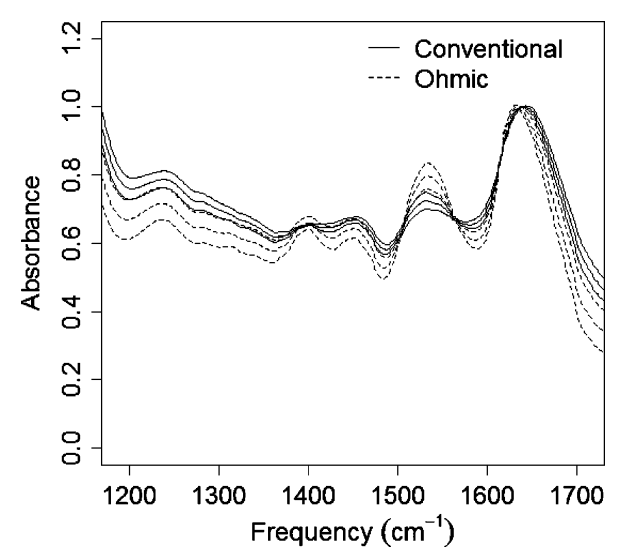

Figure 3. Comparison of FTIR absorbance spectra taken in attenuated total reflectance (ATR) mode of WPI films produced from ohmic and conventional heating.

$\theta=64.5^{\circ}$. In contrast, the "support side" surfaces of conventional and ohmic films presented similar $(p>0.05)$ contact angle values of 42.0 and $43.8^{\circ}$, respectively.

3.2.6. Fourier Transform Infrared Analysis. FTIR spectra of whey proteins, in particular, of $\beta$ - $\mathrm{Lg}$ (the most abundant in WPI) have been the subject of several publications, mostly at the spectral range of $1600-1700 \mathrm{~cm}^{-1}$, which is known as the amide I region. This region is mainly governed by the stretching vibration of $\mathrm{C}=\mathrm{O}(70-85 \%)$ and $\mathrm{C}-\mathrm{N}$ groups $(10-20 \%)$. Figure 3 shows FTIR spectra of WPI films produced by conventional and ohmic heating treatments. By deconvolution of the amide I region (Figure 4a,b), six bands in the 1618-1683 $\mathrm{cm}^{-1}$ spectral region were observed: the bands at 1619,1630 , and $1683 \mathrm{~cm}^{-1}$ correspond to $\beta$-sheet structures, ${ }^{15,55}$ whereas bands at 1644 and $1652 \mathrm{~cm}^{-1}$ correspond to unordered and $\alpha$-helix structures, respectively, ${ }^{56}$ and bands at $1670 \mathrm{~cm}^{-1}$ correspond to turns. ${ }^{57}$ Peak positions, area percentage, and assignments of bands for the different films produced are presented in Table 3 of the Supporting Information. Bands at 1618 and $1683 \mathrm{~cm}^{-1}$ are related to the formation of additional intermolecular antiparallel $\beta$-sheets during the drying step, whereas bands observed at $1630 \mathrm{~cm}^{-1}$ correspond to nativelike intramolecular $\beta$-sheet structures. ${ }^{15,55}$ For conventionally heated films, two strong bands resulted from unordered $\left(1644 \mathrm{~cm}^{-1}\right)$ and $\alpha$-helix structures $\left(1652 \mathrm{~cm}^{-1}\right)$, which correspond to a percentage area of 21.7 and $19.5 \%$, respectively. In contrast, for ohmic heated films, the two most intense bands both correspond to $\beta$-sheet structures (at 1618 and $1630 \mathrm{~cm}^{-1}$ ), which account for $>40 \%$ of the area of deconvoluted spectra. In fact, the area of components 1683,1630 , and $1620 \mathrm{~cm}^{-1}$ indicates that $49.7 \%$ of amide I region of ohmically heated films is due to intermolecular and intramolecular $\beta$-sheets, whereas $50.3 \%$ corresponds to other structures such as $\alpha$-helix, random coil segments, and turns. Conventional films presented $46.1 \%$ of $\beta$-sheets and $54.0 \%$ of the remaining structures, which is in agreement with previously published data for $\beta-\mathrm{Lg}$ films made through conventional heating of protein solutions $\left(80{ }^{\circ} \mathrm{C} / 30\right.$ min), followed by casting of the film-forming solution for dehydration. ${ }^{15}$

Once the overlapping of unordered (random coil) and $\alpha$-helix bands in amide I region made it difficult to predict accurately $\alpha$-helix contents in proteins, ${ }^{58}$ analysis of amide III band was also performed. The amide III bands, located between 1200 and $1350 \mathrm{~cm}^{-1}$, are predominantly due to the in-phase combination of $\mathrm{N}-\mathrm{H}$ in-plane bending and $\mathrm{C}-\mathrm{N}$ stretching vibrations and are known to be highly sensitive to secondary structure folding. ${ }^{59}$
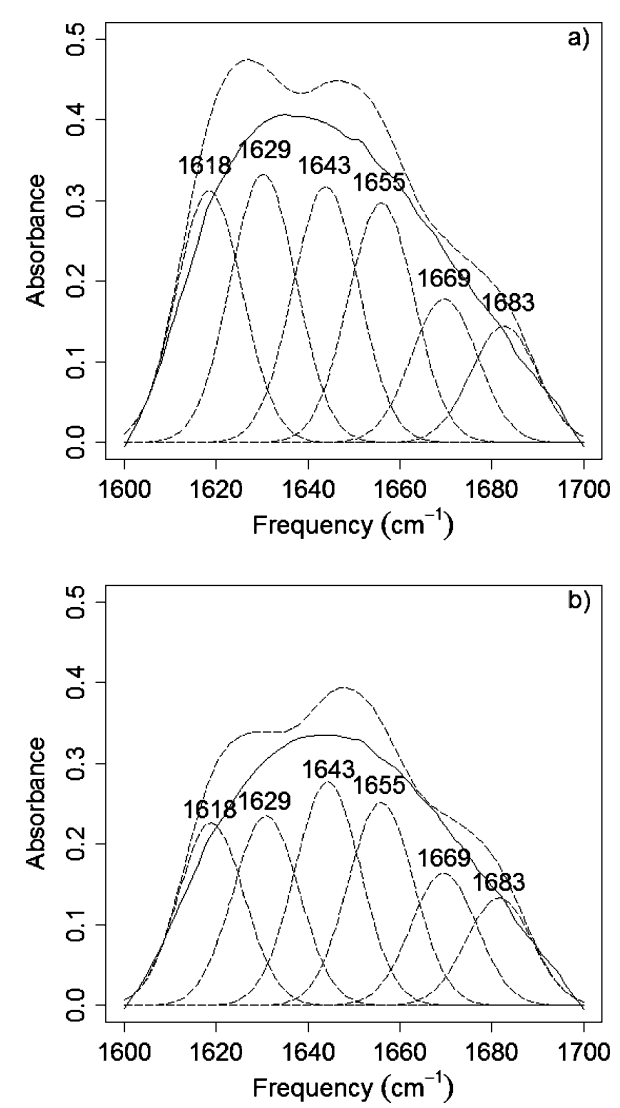

Figure 4. Fourier self-deconvolution and curve-fitting of FTIR absorbance spectra taken in attenuated total reflectance (ATR) mode in the range of amide I region, corresponding to (a) ohmic and (b) conventional films; deconvoluted (---) and original (-) spectra.

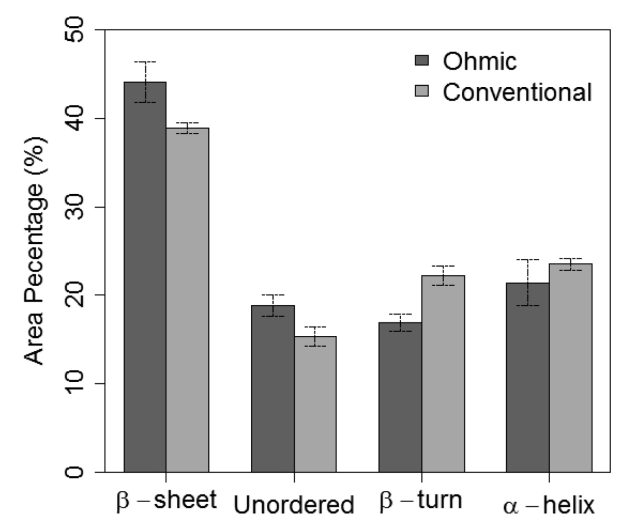

Figure 5. Band assignments and correspondent percentage area obtained after curve-fitting of the ATR spectra of conventional and ohmic WPI films in the range of amide III region $\left(1200-1300 \mathrm{~cm}^{-1}\right)$.

The signal of amide III bands is 5 to 10 times weaker than that of amide I bands but is still detectable and provides a very promising means of estimating secondary structures' content. ${ }^{58,59}$ Deconvolution of FTIR spectra from the amide III region was performed on the assumption that amide III bands are only contributed by $\beta$-sheet, unordered, $\beta$-turns, and $\alpha$-helix structures. In the spectral region between 1220 and $1310 \mathrm{~cm}^{-1}$, four bands were observed at 1236, 1248, 1264, and $1295 \mathrm{~cm}^{-1}$, which, according to published data, ${ }^{58}$ correspond to $\beta$-sheet, unordered, $\beta$-turns, and pure $\alpha$-helix structures, respectively. Figure 5 shows the area percentage contribution of the four types of protein structure in the amide III region. Results from amide III deconvolution suggest that $\beta$-sheet and $\alpha$-helix structures 
represent $>60 \%$ of protein secondary structures in both films. In fact, these results approximately match the deconvolution results of the amide I region, showing that films treated by ohmic heating present higher contents of $\beta$-sheet structure than conventional heating $(p<0.05)$ : amide III region deconvolution results show that the area percentage of $\beta$-sheet in ohmic films was $44.1 \%$, whereas the corresponding area in conventional films was $38.9 \%$. Figure 5 also shows that the contents of pure $\alpha$-helix structures were higher in conventional $(23.5 \%)$ than in ohmic films (21.4\%), but contrarily to the results obtained from amide I region, this difference was not statistically relevant $(p>0.05) . \beta$-turns and unordered structures contents also differ significantly $(p<0.05)$ in different treated films: ohmic films presented higher random coil and lower $\beta$-turns structures, $18.8 \%$ and $16.9 \%$, when compared with conventional films, $15.3 \%$ and $22.2 \%$, respectively.

\section{Discussion}

The present study clearly shows that ohmic heating interferes with the mechanisms of unfolding and aggregation or, at least, in the interactions between whey proteins. It is known that less whey protein denaturation occurs during direct heating than during indirect heating. ${ }^{29,60}$ During $\mathrm{OH}$, heat is generated directly within the food sample (volumetric or direct heating), and hence the problems associated with heat transfer surfaces are eliminated. ${ }^{61}$ Therefore, $\mathrm{OH}$ may have determined lower whey protein denaturation rates, leading to less pronounced aggregation and less activation of free $\mathrm{SH}$ groups when compared with conventional heating under similar thermal profiles. Moreover, there is no information concerning nonthermal effects of ohmic heating on whey proteins unfolding and aggregation mechanisms. To our knowledge, nonthermal effects of electric fields can be related to conformational disturbances on tertiary protein structure due to rearrangement of hydrogen bonds, hydrophobic interactions, and ionic bonds. ${ }^{62}$ The presence of moderate electric fields may affect ionic movement in the medium and influence biochemical reactions by changing molecular spacing and affecting (possibly increasing) the rates of interchain reactions. Therefore, the presence of moderate electric fields of low frequency can also dictate distinctive interactions and associations of denatured proteins that need to be further studied and verified. Until the present moment, the principal reason to which the existence of nonthermal effects of ohmic treatment has been attributed is the low frequency (50-60 Hz), which allows cell walls/membranes to build up charges that possibly interfere with their structure and functionality. $^{63}$

The results presented here suggest that the extent of WPI protein aggregation seems to influence films properties. Despite the importance of stabilizing forces, such as hydrogen bonding, on the functional properties of films made from WPI, ${ }^{2}$ heatinduced aggregates have been recently considered as the building blocks involved in the formation of protein films networks. ${ }^{15}$ Films produced by ohmic heating presented particular physical and structural properties, and this may be partially explained by different patterns of denaturation, interaction, or aggregation of whey proteins observed. The observed increase in surface hydrophilicity of treated films by ohmic heating suggests a higher availability of hydrophilic groups, which lead us to conclude that the presence of moderate electric fields may have promoted reorientation of hydrophobic clusters occurring in the proteins structure during heating and thus affecting film-forming processes.
Moreover, aggregation and, consequently, the viscosity of cast solutions may have played an important role in establishing the film thickness of ohmic films; the less viscous a solution, the more it spreads during casting and drying. ${ }^{50}$ Lower thickness values for WPI films may be an important goal from a sensory perspective, once it makes them less perceptible in a food system. $^{48}$ Furthermore, it is known that (1) aggregation of globular whey proteins in very different systems is always followed by an extensive formation of intermolecular antiparallel $\beta$-sheets ${ }^{64,65}$ and (2) $\beta$-sheet content is slightly higher for films obtained from solutions that initially contain a smaller number of heat-induced $\beta$-sheets. ${ }^{15}$ Therefore, in agreement with these observations, the lower aggregation of whey proteins registered during ohmic heating may have contributed to the slightly higher content of $\beta$-sheet structures occurring in ohmic films, providing a more crystalline character to the film. ${ }^{15,56}$

The mechanical properties observed for ohmic films are probably the result of their lower thickness, but they may also be linked to the molecular conformation of proteins. In fact, the slightly lower values of EB and TS observed for ohmic films can be related to the presence of higher contents of $\beta$-sheets in their structure once protein films exhibiting higher contents of $\beta$-sheets (such as native protein films) are known to be very brittle and friable. ${ }^{15}$ Similarly, SH groups have been positively associated with the extensibility of WPI films. In particular, the extensibility of WPI films can be reduced by reducing the presence of free $\mathrm{SH}$ in film-forming solutions. ${ }^{2}$ In agreement with this, in the present work, ohmically heated film-forming solutions presented lower quantities of $\mathrm{SH}$ groups in comparison with conventionally heated film-forming solutions.

\section{Conclusions}

Ohmic heating influenced unfolding and aggregation patterns of whey proteins, determining changes in the properties of edible films made thereof. Despite their lower thickness, ohmic heating provided films that were less permeable to water vapor and presented similar moisture barrier and nearly identical tensile properties when compared with conventional WPI films produced under identical conditions. Together with other factors such as plasticizer content, $\mathrm{pH}$, ionic strength, protein concentration, and dehydration procedure of the film forming solution, the type of heating method (direct or indirect) used for protein denaturation should not be underestimated; it may influence film properties by affecting unfolding and aggregation mechanisms of whey proteins, thus changing the distribution of secondary protein structures in the film network.

Ohmic heating may provide a novel method for production of protein films with distinctive properties; however, further research is needed for a clearer understanding of the importance of these changes on real food systems applications.

Acknowledgment. R.N.P. and M.A.C. gratefully acknowledge their Doctoral grants (SFRH/BD/31635/2006 and SFRH/ BD/23897/2005, respectively) to the Fundação para a Ciência e Tecnologia (FCT, Portugal), and B.W.S. is the recipient of a fellowship from the Coordenação de Aperfeiçoamento de Pessoal de Nível Superior (CAPES, Brazil).

Supporting Information Available. All equations referred to in the Material and Methods section and its detailed description. Tables showing the characterization of film-forming solutions, properties of protein films, and FTIR analysis. This material is available free of charge via the Internet at http:// pubs.acs.org. 


\section{References and Notes}

(1) Gounga, M.; Xu, S.-Y.; Wang, Z. J. Food Eng. 2007, 83, 521-530.

(2) Fairley, P.; Monahan, F. J.; German, J. B.; Krochta, J. M. J. Agric. Food Chem. 1996, 44, 3789-3792.

(3) Chae, S.-I.; Heo, T.-R. Biotechnol. Bioprocess Eng. 1997, 2, 122125.

(4) Seydim, A. C.; Sarikus, G. Food Res. Int. 2006, 39, 639-644.

(5) Mchugh, T. H.; Krochta, J. M. Food Technol. (Chicago, IL, U.S.) 1994, 48, 97-103.

(6) Krochta, J. M. Proteins As Raw Materials for Films and Coatings: Definitions, Current Status and Opportunities. In Protein-Based Films and Coatings; Gennadios, A., Ed.; CRC Press: Boca Raton, FL, 2002; pp $1-32$.

(7) Miller, K. S.; Krochta, J. M. Trends Food Sci. Technol. 1997, 8, 228237.

(8) Pérez-Gago, M. B.; Nadaud, P.; Krochta, J. M. J. Food Sci. 1999, 64, 1034-1037.

(9) Guckian, S.; Dwyer, C.; O’Sullivan, M.; O'Riordan, E.; Monahan, F. Eur. Food Res. Technol. 2006, 223, 91-95.

(10) Krochta, J. M. Control of Mass Transfer in Foods with Edible Coatings and Films. In Advances in Food Engineering, 1st ed.; Singh, R. P., Wirakartakasumah, M. A., Eds.; CRC Press: Boca Raton, FL, 1992. pp 517-538.

(11) Mujica-Paz, H.; Gontard, N. J. Agric. Food Chem. 1997, 45, 41014105.

(12) Banerjee, R.; Chen, H. J. Dairy Sci. 1995, 78, 1673-1683.

(13) Sothornvit, R.; Olsen, C. W.; McHugh, T. H.; Krochta, J. M. J. Food Eng. 2007, 78, 855-860.

(14) Kinsella, J. E.; Whitehead, D. M. Adv. Food Nutr. Res. 1989, 33, $343-438$.

(15) Lefevre, T.; Subirade, M.; Pezolet, M. Biomacromolecules 2005, 6, 3209-3219.

(16) Lieberman, E. R.; Gilbert, S. G. J. Polym. Sci., Polym. Symp. 1973, 41, 33-43.

(17) Mchugh, T. H.; Aujard, J. F.; Krochta, J. M. J. Food Sci. 1994, 59, 416-419.

(18) Shimada, K.; Cheftel, J. C. J. Agric. Food Chem. 1989, 37, 161-168.

(19) Castro, I.; Teixeira, J. A.; Salengke, S.; Sastry, S. K.; Vicente, A. A. J. Food Process Eng. 2003, 26, 17-29.

(20) Parrot, D. Food Technol. (Chicago, IL, U.S.) 1992, 46, 68-72.

(21) Machado, L. F.; Pereira, R. N.; Martins, R. C.; Teixeira, J. A.; Vicente, A. A. J. Food Eng. 2010, 96, 520-527.

(22) Cho, H. Y.; Yousef, A. E.; Sastry, S. K. Biotechnol. Bioeng. 1996, 49, 334-340.

(23) Icier, F.; Ilicali, C. Eur. Food Res. Technol. 2005, 220, 406-414.

(24) Lei, L.; Zhi, H.; Xiujin, Z.; Takasuke, I.; Zaigui, L. J. Food Eng. 2007, 82, 292-297.

(25) Souza, B. W. S.; Cerqueira, M. A.; Casariego, A.; Lima, A. M. P.; Teixeira, J. A.; Vicente, A. A. Food Hydrocolloids 2009, 23, 21102115.

(26) Souza, B. W. S.; Cerqueira, M. A.; Martins, J. T.; Casariego, A.; Teixeira, J. A.; Vicente, A. A. Food Hydrocolloids 2010, 24, 330335.

(27) Hoffmann, M. A. M.; Roefs, S. P. F. M.; Verheul, M.; VanMil, P. J. J. M.; DeKruif, K. G. J. Dairy Res. 1996, 63, 423-440.

(28) Ellman, G. L. Arch. Biochem. Biophys. 1959, 82, 70-77.

(29) Patrick, P. S.; Swaisgood, H. E. J. Dairy Sci. 1976, 59, 594-600.

(30) ASTM. Standard Test Method for Water Vapour Transmission of Materials (E 96-95). In Annual Book of American Standard Testing Methods; American Society for Testing: Philadelphia, PA, 1995; pp 719-725.

(31) Guillard, V.; Broyart, B.; Bonazzi, C.; Guilbert, S.; Gontard, N. J. Food Sci. 2003, 68, 2267-2277.
(32) Mchugh, T. H.; Avena-Bustillos, R.; Krochta, J. M. J. Food Sci. 1993, 58, 899-903.

(33) Gennadios, A.; Weller, C. L.; Gooding, C. H. J. Food Eng. 1994, 21, 395-409.

(34) Gontard, N.; Guilbert, S.; Cuq, J. L. J. Food Sci. 1992, 57, 190-195.

(35) Cuq, B.; Gontard, N.; Cuq, J. L.; Guilbert, S. J. Food Sci. 1996, 61, 580-584.

(36) Kwok, D. Y.; Neumann, A. W. Adv. Colloid Interface Sci. 1999, 81, $167-249$.

(37) Mangavel, C.; Barbot, J.; Popineau, Y.; Gueguen, J. J. Agric. Food Chem. 2001, 49, 867-872.

(38) R Development Core Team. R Foundation for Statistical Computing, 2.10.1 ed.; Vienna, Austria, 2009.

(39) Kazmierski, M.; Corredig, M. Food Hydrocolloids 2003, 17, 685692.

(40) Beaulieu, M.; Pouliot, Y.; Pouliot, M. J. Food Sci. 1999, 64, 776780 .

(41) O'Kennedy, B. T.; Mounsey, J. S. J. Agric. Food Chem. 2006, 54, 5637-5642.

(42) Anema, S. G.; Li, Y. J. Agric. Food Chem. 2003, 51, 1640-1646.

(43) Aboshama, K.; Hansen, A. P. J. Dairy Sci. 1977, 60, 1374-1378.

(44) Owusu-Apenten, R. Crit. Rev. Food Sci. Nutr. 2005, 45, 1-23.

(45) Cosio, M. S.; Mannino, S.; Buratti, S. J. Dairy Sci. 2000, 83, $1933-$ 1938.

(46) Owusu-Apenten, R.; Chee, C. Int. Dairy J. 2004, 14, 195-200.

(47) Koka, M.; M., M. E.; Gould, I. A. J. Dairy Sci. 1968, 51, 217-219.

(48) Longares, A.; Monahan, F. J.; O’Riordan, E. D.; O’Sullivan, M. Lebensm.-Wiss. Technol. (1968-2004) 2004, 37, 545-550.

(49) Quinn, G.; Monahan, F. J.; O’Riordan, E. D.; O’Sullivan, M.; Longares, A. J. Food Sci. 2003, 68, 2284-2288.

(50) Gennadios, A.; Weller, C. L.; Testin, R. F. Cereal Chem. 1993, 70, 426-429.

(51) Chen, H. J. Dairy Sci. 1995, 78, 2563-2583.

(52) ASTM. Standard Test Method for Tensile Properties of Thin Plastic Sheeting (D882-95a). In Annual Book of American Standard Testing Methods; American Society for Testing Materials: Philadelphia, PA, 1995; pp 182-188.

(53) Sobral, P. J. d. A. Pesqui. Agropecu. Bras. 2000, 35, 1251-1259.

(54) Vogler, E. A. Adv. Colloid Interface Sci. 1998, 74, 69-117.

(55) Eissa, A. S.; Puhl, C.; Kadla, J. F.; Khan, S. A. Biomacromolecules 2006, 7, 1707-1713.

(56) Le Tien, C.; Letendre, M.; Ispas-Szabo, P.; Mateescu, M. A.; DelmasPatterson, G.; Yu, H. L.; Lacroix, M. J. Agric. Food Chem. 2000, 48, $5566-5575$

(57) Goormaghtigh, E.; Cabiaux, V.; Ruysschaert, J. M. Eur. J. Biochem. 1990, 193, 409-420.

(58) Cai, S. W.; Singh, B. R. Biochemistry 2004, 43, 2541-2549.

(59) Anderle, G.; Mendelsohn, R. Biophys. J. 1987, 52, 69-74.

(60) Lyster, R. L. J.; Wyeth, T. C.; Perkin, A. G.; Burton, H. J. Dairy Res. 1971, 38, 403-408.

(61) Bansal, B.; Chen, X. D.; Lin, S. X. Q., Skim Milk Fouling during Ohmic Heating. In 6th International Conference on Heat Exchanger Fouling and Cleaning - Challenges and Opportunities; MüllerSteinhagen, H., Malayeri, R., Watkinson, A. P., Eds.; Engineering Conferences International Symposium Series; Kloster Irsee: Ostallgäu, Germany, 2005; Vol. RP2, pp 133-140.

(62) Castro, I.; Macedo, B.; Teixeira, J. A.; Vicente, A. A. J. Food Sci. 2004, 69, C696-C701.

(63) Sastry, S. K.; Barach, J. T. J. Food Saf. 2000, 65, 42-46.

(64) Clark, A. H.; Saunderson, D. H. P.; Sugget, A. Int. J. Pept. Protein Res. 1981, 17, 353-364.

(65) Fabian, H.; Falber, K.; Gast, K.; Reinstadler, D.; Rogov, V. V.; Naumann, D.; Zamyatkin, D. F.; Filimonov, V. V. Biochemistry 1999, $38,5633-5642$.

BM100681A 